On the orteguian condemnation of literature: presicion and speech "in partibus infidelium"

\title{
Sobre la condena orteguiana de la literatura: precisión y discurso "in partibus infidelium"
}

Francisco Javier Clemente Martín Universidad de La Laguna fclementemartin@gmail.com

DOI: http://dx.doi.org/10.15366/bp2018.18.015

Bajo Palabra. II Época. No18. Pgs: 305-320

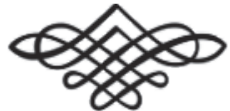




\section{Trabajo cofinanciado por la Agencia Canaria de Investigación, Innovación}

y Sociedad de la Información de la Consejería de Economía, Industria,

Comercio y Conocimiento y por el Fondo Social Europeo (FSE) Programa

Operativo Integrado de Canarias 2014-2020, Eje 3 Tema Prioritario 74 (85\%).

Recibido: 23/03/2017

Aprobado: 29/07/2018

\section{Resumen}

Este trabajo pretende esclarecer la ambigua posición que ocupa la perspectiva literaria en la obra de José Ortega y Gasset, manifiesta en la tensión que se da entre la condena explícita que hace de la literatura en algunos de sus textos y el carácter literario que posee su propia escritura. Se trata, a la postre, de sugerir una lectura alejada de las líneas interpretativas que han definido tradicionalmente los análisis de esta cuestión, incidiendo en la importancia que los elementos literarios juegan en el entramado de la filosofía de Ortega incluso a pesar de esos juicios condenatorios.

Palabras clave: Ortega, literatura, filosofía, discurso.

\section{Abstract}

This paper aims to clarify the ambiguous role of the literary perspective in the work of José Ortega y Gasset, manifested in the tension between the explicit condemnation he makes of literature in some of his texts and the literary character of his own writing. In the end, the objective is to suggest a reading away from the interpretive lines that have traditionally defined the analyzes of this issue, emphasizing the importance that the literary elements play in the framework of the philosophy of Ortega even in spite of those condemnatory judgements.

Keywords: Ortega, literature, philosophy, speech. 


\section{Ortega ante la literatura ${ }^{1}$}

LA TEMPRANA FASCINACIÓN DE ORTEGA por la literatura ha quedado caracterizada de una forma particularmente elocuente - más, incluso, que la de aquella fotografía de mocedad en la que se le puede ver imitando a Balzac - en el retrato ofrecido por su hermano Manuel al describirnos una nińez que "pasó sin cuarentena de Los tres mosqueteros a los libros de cubierta amarilla de Renan". ${ }^{2}$ Lector insaciable y perspicaz, precozmente inclinado a devorar la biblioteca paterna, Ortega acopia desde muy joven una lista casi interminable de lecturas literarias: Cervantes, Calderón, Homero y los trágicos, Mallarmé, France, Barrès y una plétora de écrivans franceses, Goethe, Shakespeare, Dostoievski y, por supuesto, prácticamente todo lo que publican sus contemporáneos... Resulta difícil concebir que esta atracción irresistible hacia las letras, esta avidez lectora oscilante entre "la formación clásica y la atención a las corrientes culturales de su tiempo", ${ }^{3}$ no encontrase su efectivo correlato en la manera orteguiana de entender y profesar la actividad filosófica; y sin embargo, la cuestión sobre el papel que juega la perspectiva literaria en el entramado de su pensamiento resulta sumamente compleja y ha suscitado no pocos desacuerdos entre sus lectores.

En efecto, la obra orteguiana está impregnada de una profunda sensibilidad literaria, lo cual puede entenderse en aquel sentido en que Morón Arroyo señalaba que el haber dado a luz algunas de las "páginas más brillantes que jamás se han escrito en español" " ha sido un mérito capaz de poner de acuerdo a la generalidad de la crítica —incluso a la condenatoria—, o en el que Juan López Morrillas afirmaba que las páginas de Ortega "figurarán entre las más bellas de la prosa castellana". 5 Van sus textos al impulso de una atención al lenguaje y a la belleza escrita inusual en la discursiva filosófica al uso, el amor a la palabra y la inquebrantable voluntad

\footnotetext{
${ }^{1}$ Las referencias a los textos orteguianos remitirán a la edición de las Obras Completas listada en la bibliografía, e irán en lo sucesivo indicadas entre paréntesis con la abreviatura $O C$ seguida del tomo en caracteres romanos y el número de página en arábigos.

2 Véase Lasaga Medina, J., "Formación”, José Ortega y Gasset (1883-1955). Vida y filosofía, Madrid, Biblioteca Nueva, 2003, p. 26.

3 Molinuevo, José L., "Filosofía y literatura”, Para leer a Ortega, Madrid, Alianza, 2002, p. 28.

4 Morón Arroyo, C., "Literatura, filosofía y sistema", El sistema de Ortega y Gasset, Madrid, Ediciones Alcalá, 1968 , p. 31.

5 López Morrillas, Juan L., “Ortega y Gasset y la crítica literaria”, en García de la Concha, V. (Ed.), Historia y crítica de la literatura española VII. Época contemporánea: 1914-1939, Barcelona, Crítica, 1984, p. 46.
} 
de estilo que los mueve configuran una idiosincrasia que no halla cobijo en el carácter meramente expositivo de la prosa filosófica convencional, sino que, antes bien, busca conmover, implicar, causar en el lector — como las buenas narraciones o poemas - un determinado pathos o afección anímica. Y así, aquella sentencia con la que Renan aceptaba que su filosofía era "poco más o menos lo que otros llaman literatura" (OC, I, 454), aquella búsqueda espiritual escindida entre la fruición estética y el rigor del pensamiento, nos abre también, como ha señalado José Luis Molinuevo, ${ }^{6}$ la "morada interior" de Ortega. En la posibilidad de conciliar ambas propensiones se pone en juego una de las claves de su pensamiento.

Diversos autores han coincidido en el diagnóstico de una tendencia ampliamente arraigada entre los estudios de la obra orteguiana a analizar aisladamente sus aspectos formales y teóricos ${ }^{7}$ —algo que no deja de resultar deshonesto con el espíritu de la misma, pues no ha de olvidarse: ya en Meditaciones del Quijote se declara el carácter consustancial de la forma y el contenido-. El vicio encuentra, según creo, una explicación plausible desde la óptica de aquella otra tendencia más amplia, denunciada reiteradamente en la actualidad por Martha Nussbaum, a considerar la preocupación por las elecciones formales más apropiadas para la exposición de una teoría como una cuestión que queda fuera de las competencias disciplinares de los filósofos, o, en el mejor de los casos, como un aspecto accesorio de su labor. ${ }^{8}$ En lo que atañe a los análisis de los elementos literarios de la filosofía orteguiana, es posible identificar dos vías hermenéuticas fundamentales: la primera de ellas, espoleada, quizás, por las reacciones enardecidas del propio Ortega ante las críticas a su escritura, se inclina a considerar que existe en su obra una contradicción manifiesta entre la búsqueda de la precisión filosófica y el uso de un lenguaje expresivo, metafórico y connotativo; la segunda, ceñida a las "pautas autocomprensivas" " que él mismo diseñó y a las que se han acogido sus exégetas de forma casi unánime, sostiene que esos elementos literarios responderían estrictamente a una intención pedagógica definida de antemano, a una mera cuestión didáctica motivada por la circunstancia nacional. ${ }^{10}$ Ambos puntos de vista van íntimamente relacionados

\footnotetext{
${ }_{6}$ Molinuevo, José L., "Literatura y filosofía en Ortega y Gasset”, Revista de Occidente, no 132, 1992, p. 73.

7 Véase Blanco, I., "El periodismo filosófico", en Zambora Bonilla, J. (Ed.), Guía Comares de Ortega y Gasset, Granada, Comares, 2013, p. 190; Martín Cabrero, Francisco J., "Agudeza y arte de ingenio en las Meditaciones del Quijote", La tradición velada. Ortega y el pensamiento humanista, Madrid, Biblioteca Nueva, 1999, p. 142; o Pérez Martínez, Ángel R., "Algunas relaciones entre literatura y filosofía en la obra de Ortega", Revista de Estudios Orteguianos, Madrid, no 24, 2012, p. 127.

8 Véase, por ejemplo, Nussbaum, Martha C., El conocimiento del amor. Ensayos sobre filosofía y literatura, Madrid, Machado Libros, 2005, p. 25.

9 Martín Cabrero, Francisco J., La tradición velada, op. cit., p. 124.

10 "Hasta ahora fue conveniente que los escritores espańoles cultivadores de esta ciencia procurasen ocultar la musculatura dialéctica de sus pensamientos filosóficos tejiendo sobre ella una película con color de carne. Era
} 
entre sí: en la medida en que hay en sus escritos una tensión aparentemente irresoluble entre filosofía y literatura -irresoluble, al menos, dentro de los parámetros convencionales de la ratio filosófica y su genus dicendi-, solo merced a una licencia pedagógica, es decir, solo como los peccata minuta del profesor que desciende a la plazuela para enseñar filosofía "a los pobres españoles, poco habituados al uso metódico de la razón", ${ }^{11}$ puede resolverse el galimatías.

Aun sin negar el peso de la intención pedagógica de Ortega, manifiesta en aquella archiconocida "cortesía del filósofo" que rehúye el lenguaje iniciático y se afana en lograr una "democratización de la filosofía", ${ }^{12}$ considero que persistir hoy en el análisis de los aspectos literarios de su obra exclusivamente desde ese punto de vista desmerece el verdadero alcance y valor de los mismos. Y si la mayor parte de la crítica no ha trascendido esta explicación, después de todo, tal vez se deba en parte a que el propio Ortega no pudo ofrecer una resolución satisfactoria al conflicto, condenando a sus escritos a vivir, como el anciano Quirón, una existencia en el quicio de dos naturalezas aparentemente antagónicas, bajo la cual se adivina aquella misma lucha encarnizada entre el compromiso filosófico y la sensibilidad poética que María Zambrano percibía en los diálogos de Platón.

\section{Precisión, literatura, $\mathbf{o} \ldots$}

UNO DE LOS FACTORES QUE MÁS HAN DEBIDO INFLUIR en esa percepción del carácter literario de la escritura orteguiana como un elemento anómalo de su obra filosófica es, probablemente, el de la ambigua posición que el propio Ortega mantuvo hacia la literatura a lo largo de su vida. A pesar de aquella fascinación lectora que le definía, a pesar incluso de que las figuras y temas literarios son recurrentes en sus trabajos o de aquella literariedad que caracteriza su escritura, no son pocas las ocasiones en las que el filósofo madrileño parece referirse al concepto de literatura con un cierto talante despectivo, al menos en lo que atañe a la posición de esta respecto al rigor de la actividad filosófica. Quizás la más célebre expresión de este aparente desdén sea aquella frase, tantas veces citada, según la cual "o se hace literatura o se hace precisión o se calla uno” (OC, I, 113). ${ }^{13}$ Con ella sentenciaba la afirmación

menester seducir hacia los problemas filosóficos con medios líricos. [...] Predomina la mente tosca que aplasta el menudo insecto de la idea articulada entre sus dedos gruesos de labriego" (OC, III, 270).

11 Martín Cabrero, Francisco J., La tradición velada, op. cit., p. 124.

12 Blanco, I., "El periodismo filosófico", Guia Comares de Ortega y Gasset, op. cit., p. 189.

13 Como ha apuntado Pedro Cerezo: "no fue Ortega enteramente consecuente con ese planteamiento dilemático, pues su estilo [...] fue un compromiso lúcido y productivo entre el rigor del pensamiento y la fuerza retórica de la imagen" (Cerezo Galán, P., "De camino hacia sí mismo”, en Guía Comares de Ortega y Gasset, op. cit., p. 29). 
de que, puestos en el dilema de tener que elegir entre la una o la otra, literatura o ciencia (y aquí ciencia conserva aquel sentido originario que engloba también a la filosofía), debemos decantarnos siempre por la última "sin pacto alguno con aquella” (OC, I, 113). Más allá de lo que podría considerarse un caso aislado, lo cierto es que los ejemplos de este tipo de formulaciones antinómicas no son precisamente escasos en su obra, llegando incluso a afirmar en correspondencia privada que "o lo has pensado [...] o es literatura". ${ }^{14}$

La cuestión se complica aún más si cabe si aceptamos aquella idea de Jordi Gracia según la cual la trayectoria filosófica de Ortega habría consistido en "defender como filosofía lo que los demás llaman despectivamente literatura, hasta que sea él mismo quien cambie de bando y ansíe escribir filosofía sin metáforas (ni literatura)" ${ }^{15} \mathrm{Y}$ es que, si fuese cierto que Ortega secundó de algún modo el rechazo filosófico a la literatura o que acabó decidido a renunciar a ella (movido, quizás, por la intuición de que a su obra le sería negado el ansiado reconocimiento mientras sus lectores siguieran interpretándola como mera literatura haciéndose pasar por filosofía, circunstancia que lamentaría amargamente en las postrimerías de su vida), cabe entonces formular una cuestión capital: ¿por qué conferir a sus textos, pese a todo, una cierta envoltura literaria? Se revela aquí la condición paradójica de una fractura entre el decir y el hacer, entre lo que afirma de lo literario en algunos de sus escritos y el cómo está escrita la amplia generalidad de los mismos; «tenemos, pues, por un lado, lo que Ortega dice en sus textos, y, por otro, lo que estos muestran». ${ }^{16}$ ¿De dónde procede esta quiebra? ¿Cómo explicarla? ¿Por qué, se pregunta Morón Arroyo, al regresar a España pertrechado del rigor germánico optó por escribir como lo hacía? ${ }^{17}$

La cuestión merece ser analizada con detenimiento. En primer lugar, creo que es posible emplear aquí un argumento análogo al que utiliza Francisco José Martín cuando trata de vincular la filosofía de Ortega con la tradición humanista a sabiendas de que se muestra crítico con ella en ciertos lugares de su obra: en esas ocasiones en que Ortega usa el término literatura con un ademán condenatorio está

14 Véase Gracia, J., “El vuelo del vencejo”, José Ortega y Gasset, Madrid, Taurus, 2014, p. 64.

15 Ibid., p. 98. Para analizar en detalle esta problemática, véase Martín Cabrero, Francisco J., "Filosofía y literatura: Ortega desde dentro", La tradición velada, op. cit., p. 51; Martín Cabrero, Francisco J., "Filosofía y literatura en Ortega”, Guía Comares de Ortega y Gasset, op. cit., p. 183; y Marías Aguilera, J., "El escritor”, Ortega. Circunstancia y vocación II, Madrid, Revista de Occidente, 1973, p. 69.

16 Martín Cabrero, Francisco J., "Raciovitalismo y tradición humanista”, La tradición velada, op. cit., p. 107.

${ }^{17}$ Morón Arroyo, El sistema de Ortega y Gasset, op. cit., p. 37. En una dirección análoga, ha escrito Francisco José Martín: “¿por qué entonces — cabría preguntar- el 'profesor de Filosofía' no se desembarazaba en su discurso de la literatura y tira su lastre por la borda para poder así elevarse y alcanzar las regiones aladas del pensamiento puro? ¿Por qué no hace corresponder su discurso filosófico con los requisitos de esa Filosofía que tan sinceramente profesa?" (Martín Cabrero, Francisco J., "Filosofía y literatura en Ortega”, Guía Comares de Ortega y Gasset, op. cit., pp. 183-184). 
empleando una cierta acepción "típica de manual de historia de la filosofía", ${ }^{18}$ está usándolo en aquel sentido lato en que equivale a lo anticientífico, irracional y falto de veracidad, se apoya en un lenguaje normalizado, en "lo consabido y comúnmente aceptado por su tiempo" ${ }^{19}$. Se vale allí, por tanto, de un sentido particular del vocablo que es ya - tanto entonces como ahora- de uso corriente, pese a ser el fruto de una línea tradicional de pensamiento a la que probablemente le ha faltado una comprensión más justa del fenómeno literario y que incluso entra en conflicto con el principio de integración que rige la propia obra orteguiana.

Literatura, en fin, en aquel sentido negativo con el que a menudo se emplea la palabra (y su campo semántico: hombre de letras, literato, etc.) incluso dentro del propio ámbito literario: se la ha hecho significar en estos casos "lo superfluo y acartonado", 20 "técnica externa y postiza [...] oficio, receta, adorno, pegote, relleno, lo no esencial". ${ }^{21}$ Es este mismo sentido específico y consuetudinario, fuente de innumerables paradojas, el que emplea Unamuno para hablar de «la cochina literatura» mientras escribe su particular Quijote, ${ }^{22}$ y también Ortega cuando se refiere a la obra de Bergson en los siguientes términos:

"género impuro, mezcla de ciencia y arte zurcidas por el capricho y la inconsciencia, lleno de afirmaciones gratuitas y de nociones rotundas, vacuas de significación —eso, en fin, que llamamos literatura- [...] hay en su obra algunos haces de equívoca literatura, desde un punto de vista científico taxativamente sin valor". ${ }^{23}$

Sobre esta crítica a Bergson, proferida en 1911, nos dice Jordi Gracia ${ }^{24}$ que provoca en el lector de Ortega un escalofrío por lo que tiene de "profecía involuntaria", y no le falta razón, pues serán juicios semejantes los que él habría de recibir poco más tarde, amén de que, como hace notar Morón Arroyo, ${ }^{25}$ esa filosofía "demimondaine" que juzga tan duramente parece corresponderse poco más o menos con la actividad que por entonces realizaba en los periódicos.

La explicación circunstancial ofrecida por Julián Marías ${ }^{26}$ para salvar esta fractura iría, según el propio Arroyo, "contra los hechos": a la altura de 1911 la noción de circunstancia está aún —nos dice— ausente en el pensamiento orteguiano, por lo que a su juicio parece poco plausible que fuese el compromiso con ella lo que moviese a Ortega a escribir de un modo que contravenía su severa concepción de

\footnotetext{
18 Martín Cabrero, Francisco J., "Introducción”, La tradición velada, op. cit., p. 24.

19 Ibid., p. 108.

20 Castagnino, Raúl H., ¿Qué es literatura?, Buenos Aires, Nova, 1972, p. 47.

${ }^{21}$ Ibid., p. 53.

22 Unamuno, M., "El sepulcro de Don Quijote", Vida de Don Quijote y Sancho, Madrid, Espasa Calpe, 1966, p. 17.

23 Véase la referencia en Gracia, J., José Ortega y Gasset, op. cit., p. 145.

24 Ídem.

25 Morón Arroyo, C., El sistema de Ortega y Gasset, op. cit., p. 37.

${ }^{26}$ Véase Marías Aguilera, J., Ortega. Circunstancia y vocación II, op. cit., pp. 125 y 137.
} 
lo literario; ${ }^{27}$ en este sentido, se decanta por la interpretación de José Gaos sobre el exceso de estímulos recibidos, sobre una voluntad sistemática constantemente asediada y refrenada por la pluralidad de frentes (regeneracionista, pedagógico, periodístico, artístico, etc.) que reclamaban su interés. ${ }^{28}$ Ese mezclarse - pese al escarnio que derrama sobre ella — con la "literatura jornalera" donde "las ideas se empuercan", respondería, así, a un forcejeo vocacional. ${ }^{29}$

$\mathrm{El}$ argumento se antoja insuficiente. Sin despreciar su porción de verdad, no parece concebible que alguien con el impulso de autenticidad de Ortega se sometiese a la disciplina periodística y literaria solo por suponer un modo de dar una cierta salida a sus múltiples vocaciones sin decantarse plenamente por ninguna de ellas. Para entender que contradijese con su forma de escribir sus propios juicios sobre la literatura (y es importante hacer notar que él mismo no reconocía tal contradicción, consideraba, más bien, que eran sus lectores quienes resbalaban sobre su escritura sin alcanzar el fondo de la misma), ${ }^{30}$ no parece que baste aceptar que el periódico y la escritura bella constituyesen la única vía posible para dar salida a esa multiplicidad de intereses. Ha de existir una razón más profunda y elemental que sea capaz de dar cuenta de la aparente contradicción que representa su obra.

Francisco José Martín ha indicado que Ortega se quedó a las puertas de resolver la dialéctica clásica entre literatura y filosofía; no lo logró, afirma, pese a haber dispuesto los materiales que ello habría requerido (una obra que es ya en sí misma valedora activa de la integración entre lo literario y lo filosófico, la temprana declaración del carácter indisociable entre forma y fondo en el terreno de las artes, etc.) porque habría permanecido inserto, pese a todo, en una línea tradicional de pensamiento en su forma de conceptualizar la relación entre ambas nociones. De ahí que, puesto el problema de esta relación sobre la mesa, declare que "al pensar, el lenguaje se transforma en puro soporte de las ideas, de suerte que solo estas quedan —o deben quedar - visibles, mientras que el lenguaje está destinado a desaparecer en la medida de lo posible" (OC, IX, 635), y con esta afirmación parezca demoler el edificio entero magníficamente constituido con su obra. ${ }^{31}$

\footnotetext{
27 "La idea de circunstancia como piedra angular de su pensamiento brilla por su ausencia en este período" (Morón Arroyo, C., El sistema de Ortega y Gasset, op. cit., pp. 37-38). La cuestión, no obstante, resulta más compleja de lo que pudiera parecer. Véase Marías Aguilera, J., Ortega. Circunstancia y vocación II, op. cit., p. 159. Es cierto que la noción carece por esa fecha del desarrollo y la centralidad que va adquirir en las Meditaciones del Quijote; pero no menos cierto es que ello no menoscaba necesariamente esa preocupación circunstancial que Marías atribuye a la obra del joven Ortega.

${ }_{28}$ Morón Arroyo, C., El sistema de Ortega y Gasset, op. cit., pp. 38-39.

29 Ídem.

30 "Ortega, como Fray Luis y los 'clásicos' del siglo XVI, no sentía disparidad alguna entre la riqueza de la forma y la exactitud conceptual” (Marichal, J., La voluntad de estilo, Barcelona, Seix Barral, 1957, p. 263).

31 Martín Cabrero, Francisco J., La tradición velada, op. cit., pp. 85-87 y 107. Insiste con énfasis este autor en la idea de que la incapacidad de Ortega para resolver la oposición tradicional entre literatura y filosofía responde
} 
Esta vía parece más prometedora: Ortega está convencido de que lo que él hace, no importa la consideración que tengan sus críticos, no es literatura; y lo está, precisamente, porque acepta como punto de partida aquella distinción tradicional en el marco de la cual lo literario aparece, por definición, como escritura sin veracidad ni fundamento. ${ }^{32}$ Quizás le habría bastado con cuestionar esa misma oposición y ese mismo matiz semántico para defenderse de sus críticos (aquellos que, considerándolo literato, han creído menoscabar el valor de su pensamiento), quizás debió haber adoptado una posición menos rígida y conservadora a la hora de explicitar algunas de sus consideraciones sobre la literatura, lo cual podría haberle supuesto aliviar la tensión inherente a su obra y reconocer la absoluta pertinencia de esos elementos literarios que brotaban de su propia filosofía. Pero no lo hizo, permaneció sujeto al arrastre de la corriente generada por cierta visión escolástica que no terminó de someter decididamente a examen crítico, y en consecuencia, no logró resolver con sencillez "esa tensión entre la filosofía y la literatura de que son tan característicos sus textos, y ante la que él mismo, en ocasiones, se manifestó con inquietud y desasosiego, y de la que no siempre dio muestras de asumir de manera serena". ${ }^{33}$

He aquí aquella explicación primaria y fundamental: hay en Ortega una pulsión creadora, poética, que se le impone en su forma de hacer filosofía, a la cual corresponde una cierta forma integral de ser, un estilo, y ese estilo es irreconciliable de facto con ciertos retales de tradición — ciertas creencias, y entiéndase aquí la palabra en la plenitud de su sentido orteguiano- que permanecen operantes en algunos de sus juicios. Ortega cree, como heredero de la cultura de su tiempo, que filosofía y literatura son cosas distintas y necesariamente contrapuestas; y, sin embargo, cuando se trata de dar forma a sus ideas genuinas, de pergeñar su propio pensamiento, esta creencia parece disolverse, desdecirse y ceder lugar a una espontánea y dinámica integración de lo literario y lo filosófico. Y la clave que esclarece este aparente contrasentido reside en que no alcanza - pese a lo cerca que se queda de ello- a reformular la relación de manual entre filosofía y literatura, quiero decir,

al hecho de que seguía, pese a todo, bajo el influjo de la fe moderna en la razón: se trataba de reubicarla, de "ponerla en su lugar» en relación a la vida, al servicio de esta y arraigada en ella; pero, al fin y al cabo, el raciovitalismo seguiría, a su juicio, posicionando esa razón en un lugar preeminente sobre las demás facultades del espíritu (véase ibid., pp. 98-99 entre otras).

32 En relación a este distanciamiento consciente y deliberado de Ortega respecto a la literatura, véase Martín Cabrero, Francisco J., "Filosofía y literatura en Ortega", Guía Comares de Ortega y Gasset, op. cit., p. 180.

33 Martín Cabrero, Francisco J., La tradición velada, ob. cit., p. 107. Con respecto a los exabruptos de Ortega frente a quienes malentendían la condición literaria de sus escritos, ha observado José Lasaga: "esta reacción malhumorada no puede ocultar que Ortega nunca se sintió cómodo ante su obra publicada”. Y ańade la interesante hipótesis de que tal vez el sistemático incumplimiento de sus promesas de una gran obra venidera se debiera a que "dejó de creer que fuera posible una filosofía de la vida humana estructurada según las convenciones del 'sistema escolar". Véase Lasaga Medina, J., "La madurez del filósofo: los cursos de los años treinta", Guía Comares de Ortega y Gasset, op. cit., p. 74. 
a explicitar una reflexión superadora de esta dicotomía esencial, a aclarar en qué consiste exactamente esa literatura que condena y en qué se diferencia de lo que a él le recriminaban por tal. ${ }^{34}$

Ahora bien, de todo lo anteriormente expuesto se desprende una importante conclusión, y es que, dejando a un lado la — a menudo excesiva — dureza de algunos de sus juicios contra la literatura y contra los literatos, es manifiesto que Ortega no se opone, en cualquier caso, a la escritura bella (a la cual el lenguaje al uso tiende a dar también el nombre de literatura), se opone a la escritura vacua, y por la inercia que imprime cierta manera común de hablar y de pensar, le pone la etiqueta de lo literario. Esto nos conduce a una segunda consideración en relación al problema de aquella aparente contradicción entre el decir y el hacer: los elementos que pueden tomarse por literarios en los textos orteguianos van, en su generalidad, orientados por un imperativo de exigencia, responden a la búsqueda permanente de un "ideal literario de utilidad". ${ }^{35}$ Existen sobradas muestras del valor filosófico que Ortega concede a lo literario en su obra - baste considerar que busca en Cervantes la clave del destino y la regeneración de la cultura española—, pero ese valor se constituye en la capacidad de "resistir el rigor técnico", que es "el criterio de la veracidad" (OC, I, 111). Aquella frase, "o se hace literatura o se hace precisión o se calla uno", fue proferida en el contexto de un debate con Maeztu sobre la imprecisión intelectual española; solo así, contextualizada, puesta en circunstancia, cobra su verdadera significación, y solo así puede entenderse que sea precisamente Ortega quien diga que "[el] método literario sí que hace daño a España" (ibíd., 112). Lo que suscita sus críticas hacia ese "método literario" que asumían sus coetáneos no es, desde luego, el cuidado de la escritura, sino la escritura puesta al servicio del capricho y el culto romántico a la subjetividad hipertrofiada. "El hombre sincero cuenta lo que en realidad sienten sus nervios y con ello cree haber cumplido", afirma, "el hombre veraz

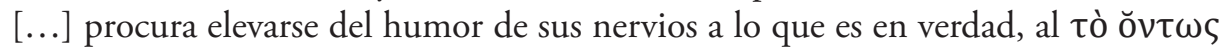
ŏv platónico" (ibíd., 111). ${ }^{36}$ Puede concluirse, por consiguiente, que el amor a la

\footnotetext{
34 Entre las notas de trabajo de Ortega encontramos este revelador precepto: "no protestar jamás la estúpida e insincera actitud de los que fingen despreciar la claridad de la expresión del pensamiento y las cualidades estéticas (lo que no significa sin más ni más 'iterarias') de un libro de filosofía" (Ortega y Gasset, J., "Notas de trabajo", Revista de Occidente, no 132, 1992, pp. 64-65). La frase que destaco en cursiva denota el énfasis que pone Ortega en marcar distancias respecto a la literatura (véase nota 33). Ahora bien, ¿qué significa, "sin más ni más", literatura? ¿Cuál es la definición precisa de esa literatura de la que se distancia? Es en este punto donde faltó a Ortega, quizás, una reflexión pormenorizada.

35 Mainer, Juna C., "La crítica intelectual a los noventayochistas y la Revista España", Historia y crítica de la literatura española VII, op. cit., p. 25.

36 Julián Marías ha observado con gran acierto que la cruzada orteguiana de estos ańos contra la literatura, la sinceridad y la retórica se dirige hacia lo que circunstancialmente se tenía por tales nociones: la lucha de Ortega es, en realidad, contra la "voluntad de chabacanería y falta de rigor", y frente a ella, "va a reivindicar la veracidad" (Marías Aguilera, J., Ortega. Circunstancia y Vocación II, op. cit., p. 95). José Luis Molinuevo, por su parte, ha
} 
palabra es fundamental aquí en tanto adscrito a la voluntad de veracidad, ${ }^{37}$ que puede hacerse "precisión" al tiempo que se hace literatura siempre que esta vaya preńada de un impulso clarificador. ${ }^{38}$ Es cierto que Ortega no siempre ratifica esta idea con sus palabras, pero la ejecuta escrupulosamente en sus textos.

Si cabe recriminarle algo, en definitiva, es el haber perpetuado el uso de la denominación literatura en aquel sentido con el que la deriva moderna le adscribió irremediablemente falta de veracidad y rigor, y que aún operaba con plena vigencia en su tiempo. ${ }^{39}$ A Ortega, quien alcanzó una unidad de estilo donde lo retórico hace valer su particular pertinencia en el entramado significativo del texto, le faltó una reflexión explícita que desanduviese el camino de lo escrito y se hiciera cargo de la relación literatura-filosofía no ya según la "dicotomía disciplinar", ${ }^{40}$ sino en función de lo que acontecía en sus propios escritos. Le faltó, quizás, aquello que Julián Marías ha señalado como un acierto orteguiano al abordar otras cuestiones, a saber: ir por debajo del supuesto para "descubrir los suyos y mostrar que no son sostenibles ni suficientes". ${ }^{41} \mathrm{Y}$ es aquí donde resulta conveniente asumir el criterio procedimental sugerido por Francisco José Martín de "prescindir del principio de autoridad que se concede respecto de un texto a su autor". ${ }^{42}$

En una nota aneja de Origen y epílogo de la filosofía puede leerse lo siguiente:

"¡Yo he tenido que aguantar en silencio durante treinta años que los tontainas me acusen de no hacer más que literatura, y lo que es peor, que mis discípulos mismos, crean debido plantear la cuestión de si lo que yo hacía era literatura o filosofía o ridiculeces provincianas de este jaez!" (OC, IX, 404).

incidido en cómo la crítica juvenil de Ortega hacia la literatura responde, fundamentalmente, al cuestionamiento de la tradición literaria francesa y de los ideales noventayochistas (véase Molinuevo, José L., «Literatura y filosofía en Ortega y Gasset», op. cit., pp. 71-73).

37 Como subraya Pedro Cerezo, «el acento había, pues, que ponerlo, según Ortega, en el valor objetivo de la cultura” (Cerezo Galán, P., “De camino hacia sí mismo”, en Guía Comares de Ortega y Gasset, op. cit., p. 29).

38 Nos recuerda Francisco José Martín, en este sentido, que «a él toca salvar la literatura. Es exigencia moral de su propio pensamiento, de su propia filosofía, de esa filosofía creadora que funda el proyecto general de las Meditaciones» (ibid., p. 185).

39 “Entre 1920 y 1935, aproximadamente, la palabra proscrita entre los escritores españoles era... 'literatura', que entonces se oponía a 'poesía' y no suscitaba sino desprecio. Por las mismas fechas — quizás unos años antes-, esa función la había desempeñado 'retórica', con un área un poco más amplia: quiero decir que se llamaba 'literatura' a toda poesía inauténtica, y se reservaba 'retórica' para descalificar todo escrito — verso o prosa- que no satisfacía las exigencias del momento" (Marías Aguilera, J., Ortega. Circunstancia y vocación II, op. cit., p. 93). Para un estudio en profundidad de la problemática concepción orteguiana de la retórica, véase Martín Cabrero, Francisco J., «El significado filosófico de la retórica», La tradición velada, op. cit., particularmente las pp. 137 y 138.

40 Martín Cabrero, Francisco J., "Agudeza y arte de ingenio en las Meditaciones del Quijote", La tradición velada, op. cit., p. 141.

41 Marías Aguilera, J., Ortega. Circunstancia y vocación II, op. cit., p. 176.

42 "Ningún autor puede avanzar un derecho de prioridad sobre las interpretaciones de sus textos [...]. Más allá de su autor, los textos siguen dialogando, con otros textos o con cuantos interlocutores quieran acercarse a ellos" (Martín Cabrero, Francisco J., La tradición velada, op. cit., p. 124). 
Estimo que resulta conveniente adoptar una actitud crítica hacia esta sentencia. Porque precisamente en el hecho mismo de "plantear la cuestión", de afrontarla sin evasivas, encarando la tarea de revisar el tópico manualístico de la supuesta incompatibilidad entre filosofía y literatura, radica la plenitud de sentido de aquella peculiar forma de expresarse que le caracterizaba y una disolución no forzada de la tensión definitoria de sus escritos. Urgía, por cuanto tiene de equívoco y ambiguo, una clarificación del concepto de literatura que Ortega no llegó a ofrecer plenamente, permaneciendo sujeto a un cierto uso habitual del término; y así, aun cuando afirme, en relación a quienes trataban de definirle inequívocamente con la etiqueta de literato o de filósofo, que "pájaros de hogaño no se pueden cazar con redes de antańo", ${ }^{43}$ se retuerce y hace contorsiones para zafarse de la red tosca y torpemente zurcida de una dicotomía tradicional incapaz, en cualquier caso, de atrapar el vuelo alado de su escritura. ${ }^{44}$ Quizás el camino más corto y fecundo para defenderse de sus críticos hubiera sido aceptar, en su plena y radical significación, la condición literaria de su obra, y con ello desmantelar aquella equiparación entre literatura e inexactitud de la que en ocasiones se mostró partidario. Un sí rotundo y enérgico a la literatura, a una literatura que no significaba ya capricho y vaguedad a la manera que afirmaba el lugar común, sino voluntad metafórica y una necesaria sensibilidad para lo concreto y cambiante por agotamiento de lo ubicuo y perenne.

Cabe añadir una apreciación más en relación a esta problemática: cuando se achaca a Ortega la presunta contradicción que supone militar a favor del rigor germánico y no terminar, pese a ello, de desprenderse del componente literario nutrido de la circunstancia nacional, se pasa por alto que la voluntad de europeización de la cultura española que defiende su obra juvenil no significaba una rendición incondicional a los fundamentos de la gran filosofía europea. No debe olvidarse que en ese movimiento hacia Europa va comprendida ya la salvación del espíritu español. ${ }^{45}$ En ocasiones no se ha reparado adecuadamente - y al hacerlo, se ha desmerecido su auténtico sentido - en lo que implica la convergencia de la cultura hispánica con un proyecto cultural europeo a la manera que propugna

43 ORtega y Gasset, J., "Notas de trabajo", op. cit., p. 65.

${ }^{44}$ La "pregunta insidiosa" por la condición literaria o filosófica de la obra de Ortega, ha escrito Francisco José Martín, era "la trama de una emboscada de la que no supo —o no pudo— escapar. [...]El mismo Ortega tardó en darse cuenta. Sintió la mordedura de su impertinencia, pero con su lamento aceptaba su justicia" (Martín Cabrero, Francisco J., "Filosofía y literatura en Ortega", Guía Comares de Ortega y Gasset, op. cit., p. 172).

45 Afirmaba María Zambrano, en relación a Ortega, que "el hecho de ser un filósofo que, desde su primera juventud, se plegó a la disciplina filosófica más estricta - la escuela neokantiana de Marburgo- ha ofuscado con frecuencia la atención de los que consideran su obra y su acción, impidiéndoles ver esa fidelidad inicial a la tradición espańola de pensamiento" (Zambrano, M., "Ortega y Gasset, filósofo español”, España, sueño y verdad, Barcelona, Edhasa, 2002, p. 115). Y es que, en rigor, se trataba de lo siguiente: "era necesaria esta inmersión en la filosofía para poder luego hacerla desde la 'originalidad' de España. [...] Provisto de la estricta disciplina europea, se dispuso a ser un español que mira" (ibid., p. 113). 
la obra orteguiana: Ortega busca salvar la tradición patria, no se trata de negarla para adscribirse incondicionalmente a los postulados de la filosofía moderna, pues también esta había de ser superada (OC, I, 209), reformulada desde sus principios elementales —incluyendo aquí su lenguaje—; no hay contradicción alguna, por tanto, en propender hacia el rigor germánico desde el horizonte filológico y artístico que las letras españolas habían abierto a la actividad filosófica. Se trataba de una integración y una puesta a punto por y desde ambas partes, no de una deserción. Tomadas aisladamente, las críticas de Ortega a la ambigua noción de literatura pueden conducir a esta conclusión equivocada.

\section{Conclusiones}

Lo QUE ES INNEGABLE, AL MARGEN DE ENREDOS terminológicos, es que su obra concede un papel preminente a lo literario y que hay claves suficientes en ella como para desentrañar este valor y potenciarlo, más allá incluso de algunas de las afirmaciones proferidas por el propio Ortega. Los estudios de su obra han de asumir el compromiso de no seguir atendiendo a la vertiente literaria de esta como un aspecto marginal, extraño, decorativo, devaluador o puramente didáctico de su filosofía; solo en un sentido cabe hoy rescatar esa relación tan íntima que se da en sus escritos entre lo filosófico y lo poético: como el testimonio de una filosofía - la de la razón vital— que busca implicar al hombre por entero, ya no apelando a una razón aislada en la frialdad de su recinto fortificado, sino en la plenitud de su condición patética y vital. Una filosofía, por tanto, que no podría valerse, sin resultar profundamente incoherente con sus principios fundamentales, de esa retórica sistemática, expositiva e impersonal que la tradición ha blindado como único modelo discursivo filosóficamente válido. ${ }^{46}$

El lenguaje literario, ha sugerido Martha Nussbaum, apunta con particular énfasis al plano afectivo-emocional de la vida humana y está especialmente capacitado para dar cuenta de lo inmediato y diverso. ${ }^{47} \mathrm{Nada}$ más justo, por consiguiente, que el hecho de que ese esfuerzo tan característico de la obra orteguiana por corregir los excesos de una filosofía moderna "enferma de presbicia" — afanada en construir ideales grandilocuentes y abstractos mientras descuida cuanto atañe a la dimensión

\footnotetext{
46 "La historia de la filosofía no es más que una narración de una sucesiva contienda entre los distintos 'modos de pensar' por la conquista del dominio del espacio intelectual. Esa narración refleja siempre el punto de vista del vencedor" (Martín Cabrero, Francisco J., "Pensar desde la lengua. A propósito del paradigma de la 'tradición velada”, Revista de Occidente, Madrid, no 394, 2014, pp. 10 y 11).

${ }^{47}$ Véase Nussbaum, Martha C., Justicia poética. La imaginación literaria y la vida pública, Barcelona, Andrés Bello, 1997, p. 85, y "La imaginación literaria en la vida pública”, Isegoría, 11, 1995, p. 45.
} 
inmediata de la vida - se configure en un lenguaje vivaz y conmovedor, capaz de despojar a la teoría de su "tonalidad en gris menor" y colmarla de jovialidad. Desde este punto de vista puede entenderse aquella afirmación de Julián Marías según la cual "solo con literatura se puede lograr cierta precisión superior", ${ }^{48}$ o lo que es lo mismo, "para hacer precisión verdadera no hay más remedio que hacer literatura". ${ }^{49}$ Porque "precisión verdadera" no significa aquí más que el esfuerzo por revitalizar el lenguaje, despojándolo de la costra sedimentaria que adquiere en su uso corriente, haciéndolo más próximo y vividero. Un pensamiento que trata de ofrecer reconocimiento a nuestra condición sintiente y a la multiplicidad inagotable de perspectivas en que se configura la realidad humana requiere de un lenguaje decididamente metafórico y expresivo.

Forma y fondo actúan conjuntamente en una unidad teórico-formal irreductible. Ortega lo sabía, y por ello emprendió su particular batalla contra aquellos que le recriminaban el lirismo de su escritura. El célebre episodio de la "corbata vistosa" lo pone de manifiesto: es consciente de que su forma de escribir no es impostada ni responde a una intención ornamental o estrictamente pedagógica, antes bien, está inscrita de forma indeleble en su mismo ser, en su singularísima posición ante el mundo, en la autenticidad de su filosofía; de ahí que, acusado de no ostentar con su discurso más que un adorno tan colorido como superficial, recurra a la sugestiva metáfora de la columna vertebral que se le transparenta como forma de afirmarse en la genuinidad de su decir.

$\mathrm{Y}$, sin embargo, esta clarividencia a la hora de identificar la profunda implicación que se da entre la forma y el contenido no la llevó Ortega a sus últimas consecuencias, no le bastó para formular una propuesta capaz de desmantelar aquel tópico cuyos fundamentos tienen hoy cada vez más visos de resultar insostenibles- sobre la absoluta incompatibilidad entre el lenguaje literario y la voluntad filosófica. Sus páginas parecen estar a cada instante a punto de lograrlo, se intuye a través de la textualidad orteguiana el advenimiento de una teoría capaz de hallar un espacio de convergencia entre ambas potencias. Y esa tarea que permanece incompleta en su obra publicada puede aún ser retomada por sus lectores, lo cual exige tanto el reconocimiento del carácter anticipatorio y pionero de sus escritos en lo que respecta a la efectiva integración que se da en ellos entre lo filosófico y lo literario, como el replanteamiento de algunas de sus consideraciones explícitas sobre la literatura.

\footnotetext{
48 Marías Aguilera, J., Ortega. Circunstancia y vocación II, op. cit., p. 19.

49 Ibid., p. 40.
} 


\section{Referencias Bibliográficas}

Castagnino, Raúl Héctor, ¿Qué es literatura?, Buenos Aires, Nova, 1972 García de la CONCha, Víctor (Ed.), Historia y crítica de la literatura española VII. Época contemporánea: 1914-1939, Barcelona, Crítica, 1984

Gracia, Jordi, José Ortega y Gasset, Madrid, Taurus, 2014

Lasaga medina, José, José Ortega y Gasset (1883-1955). Vida y filosofía, Madrid, Biblioteca Nueva, 2003

Marías Aguilera, Julián, Ortega. Circunstancia y vocación II, Madrid, Revista de Occidente, 1973

Marichal, Juan, La voluntad de estilo, Barcelona, Seix Barral, 1957

Martín Cabrero, Francisco José, "Pensar desde la lengua. A propósito del paradigma de la 'tradición velada", Revista de Occidente, no 394, 2014

- La tradición velada. Ortega y el pensamiento humanista, Madrid, Biblioteca Nueva, 1999

Molinuevo, José Luis, "Literatura y filosofía en Ortega y Gasset", Revista de Occidente, no 132, 1992

- Para leer a Ortega, Madrid, Alianza, 2002

Morón Arroyo, Ciriaco, El sistema de Ortega y Gasset, Madrid, Ediciones Alcalá, 1968

Nussbaum, Martha Craven, El conocimiento del amor. Ensayos sobre filosofía y literatura, Madrid, Machado Libros, 2005

— "La imaginación literaria en la vida pública”, Isegoría, 11, 1995

- Justicia poética. La imaginación literaria y la vida pública, Barcelona, Andrés Bello, 1997

Ortega y Gasset, José, Obras Completas, Madrid, Revista de Occidente, 19641966

— "Notas de trabajo", Revista de Occidente, no 132, 1992

Pérez Martínez, Ángel Rubén, "Algunas relaciones entre literatura y filosofía en la obra de Ortega", Revista de Estudios Orteguianos, n 24, 2012 
Unamuno, Miguel de, Vida de Don Quijote y Sancho, Madrid, Espasa Calpe, 1966

Zambrano, María, España, sueño y verdad, Barcelona, Edhasa, 2002

Zamora Bonilla, Javier (Ed.), Guia Comares de Ortega y Gasset, Granada, Comares, 2013

DOI: http://dx.doi.org/10.15366/bp2018.18.015

Bajo Palabra. II Época. No18. Pgs: 305-320 